\title{
Study by proponent of neck vein-widening therapy for MS finds treatment ineffective
}

\author{
— Cite as: CMAJ 2018 January 8;190:E28-9. doi: 10.1503/cmaj.109-5539
}

Posted on cmajnews.com on Dec. 7, 2017.

$\mathrm{T}$ he controversial "liberation therapy," which aims to treat multiple sclerosis (MS) by widening narrowed veins in the neck and chest, has been dealt a blow by its main backer.

A large-scale randomized clinical trial of venous percutaneous transluminal angioplasty (PTA) found that it is ineffective in treating the neurological condition. The a cause of MS and that widening them could treat the disease.

The procedure was never approved for treatment of MS in Canada, but some patient groups enthusiastically embraced the idea. Thousands of Canadians are thought to have travelled to the United States or Europe since 2009 seeking the intervention.

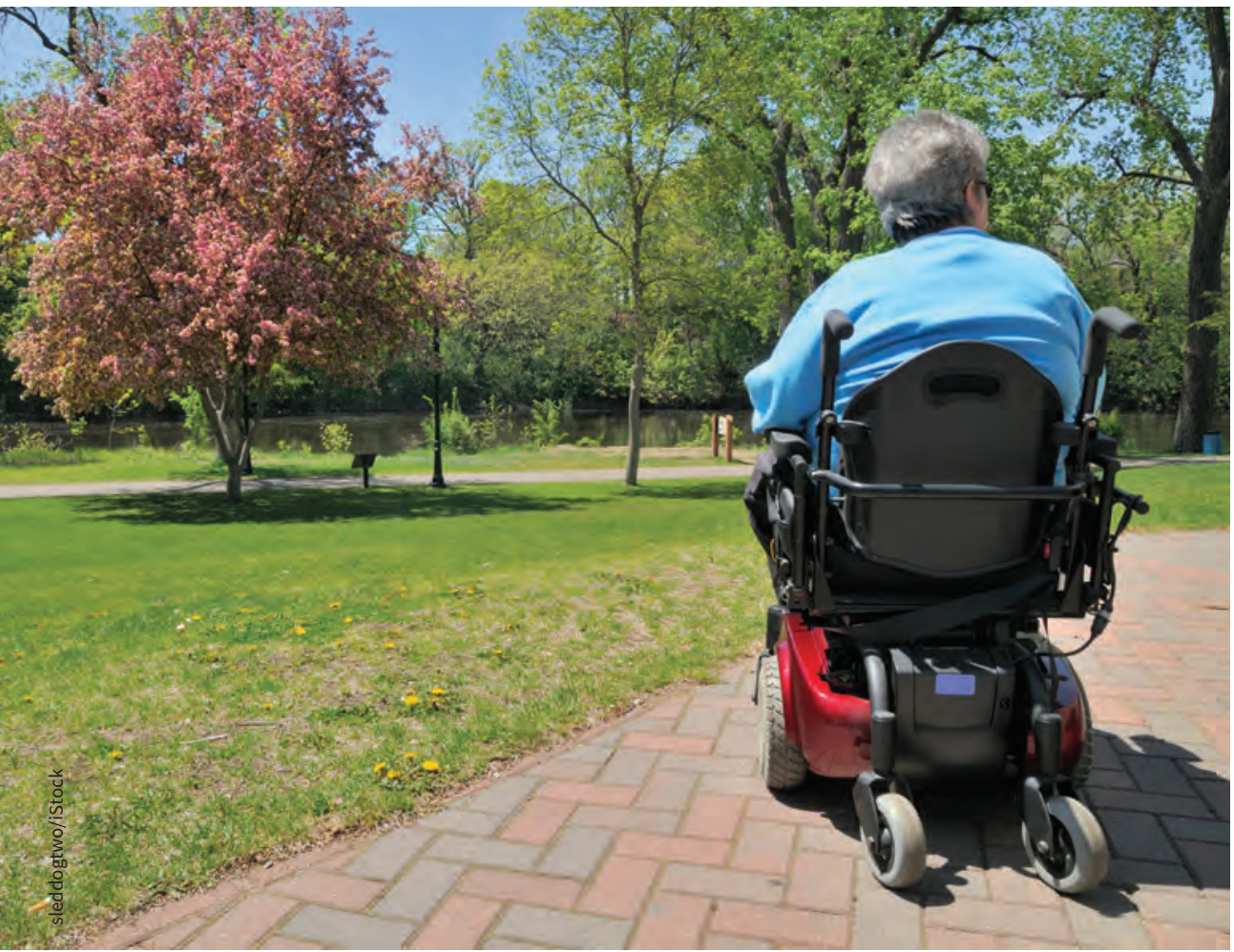

Despite enthusiasm about the procedure from some patients, liberation therapy has been proven ineffective for treating multiple sclerosis.

study, published in JAMA Neurology, was led by Dr. Paolo Zamboni - the Italian vascular surgeon who first suggested, in 2009, that narrowed veins in the head and neck, a condition he dubbed chronic cerebrospinal venous insufficiency (CCSVI), could be
The new clinical trial involved 115 patients with relapsing-remitting MS and CCSVI at six MS centres in Italy. Twothirds of them underwent PTA; the others had a sham surgery as a control in a double-blind trial. After 12 months, there was no significant difference between the two groups, either in clinical status or the appearance of new lesions. "Venous PTA has proven to be a safe but largely ineffective technique; the treatment cannot be recommended in patients with MS," the study concluded.

"I accepted, of course, the result of the clinical experiment," said Zamboni. But the sample size was too small to give a conclusive result, he added. The plan was to have 400 participants. Also, although there was no effect on disability recovery, some patients who received angioplasty had fewer new lesions after six months, though that effect essentially disappeared by 12 months, said Zamboni.

Zamboni said he will continue to study the link between CCSVI and neurological conditions. "I am fascinated by the study of venous and lymphatic drainage of the brain, and I will certainly continue and contribute to this line of research, still in its infancy."

Dr. Anthony Traboulsee, a neurologist at the University of British Columbia, said he is not concerned about the statistical power of Dr. Zamboni's trial: enough patients completed the trial and the outcome was not in doubt. On the most important measure - whether those who underwent treatment felt improvement there was "not even a hint of difference" between the intervention and control groups, he added.

The lack of positive evidence does not surprise Traboulsee. He recently completed a similar study on 104 patients with MS in Canada, which also found no significant difference in patient-reported improvements between the treatment and control groups, and no difference in the number of new lesions. The results 
were presented at a scientific conference and are undergoing peer review for publication in a medical journal.

Traboulsee commends Zamboni for his commitment to testing his ideas rigorously. "A lot of people throw ideas out there, but never take the next step of doing randomized trials," he said.

The fact that Zamboni was involved in the Italian trial and had similar results to the Canadian one helps validate Traboulsee's own work, he added. "There was some concern [among advocates] that we would be biased, and we're just trying to disprove it," he said. "That was not the goal."

Actually, the negative results for PTA treatment are disappointing, said Traboulsee, especially given the number of people with the disease in Canada, which has the world's highest rate of MS. "It's really too bad this didn't help people with MS," he said. "Wouldn't it be great if we had something that could actually improve people's lives? This just wasn't it."
Interest in liberation therapy has been waning in Canada over the past couple of years, said Dr. Traboulsee, since research found that rates of CCSVI are no higher in people with MS than in the general public. Also, anecdotal reports from those who had undergone the treatment indicated that any improvements in symptoms were short-lived. He hopes that the two new studies will dissuade those still considering the treatment.

Brian Owens, St. Stephen, NB 